\title{
The effect of bilio-pancreatic diversion on type 2 diabetes in patients with $\mathrm{BMI}<35 \mathrm{~kg} / \mathrm{m}^{2}$
}

\author{
C. Chiellini • F. Rubino $\cdot$ M. Castagneto $\cdot$ G. Nanni • \\ G. Mingrone
}

Received: 26 January 2009 / Accepted: 4 March 2009/Published online: 24 March 2009

(C) Springer-Verlag 2009

\begin{abstract}
Aims/hypothesis To aim of the study was to investigate the effect of bilio-pancreatic diversion (BPD) on type 2 diabetes in patients with $\mathrm{BMI}<35 \mathrm{~kg} / \mathrm{m}^{2}$.

Methods OGTTs were performed and anthropometric data were compared between five diabetes patients (BMI 27$33 \mathrm{~kg} / \mathrm{m}^{2}$ ) following BPD and seven diabetes patients after a low-energy diet. Insulin secretion was computed by C-peptide deconvolution. A euglycaemic-hyperinsulinaemic clamp was performed only in the BPD group and the $M$ value measured.

Results One month after BPD, fasting and $2 \mathrm{~h}$ postOGTT glycaemia decreased from $15.22 \pm 3.22$ to $6.22 \pm$ $0.51 \mathrm{mmol} / 1(p=0.043)$, while insulin sensitivity increased significantly. No significant changes were observed in the low-energy diet group. Insulin secretion did not differ significantly after either intervention. Diabetes amelioration (change in $\mathrm{HbA}_{1 \mathrm{c}}$ level) was observed up to 18 months after BPD without pharmacological therapy.

Conclusions/interpretation BPD can achieve adequate control of type 2 diabetes also in patients with BMI $<35 \mathrm{~kg} / \mathrm{m}^{2}$. The rapid postoperative remission of diabetes is primarily related to an improvement in insulin sensitivity.
\end{abstract}

C. Chiellini $\cdot$ G. Mingrone $(\bowtie)$

Department of Internal Medicine, Catholic University,

Largo A. Gemelli, 8,

00168 Rome, Italy

e-mail: gmingrone@rm.unicatt.it

F. Rubino

Weill Cornell Medical College/New York Presbyterian Hospital,

New York, USA

M. Castagneto $\cdot$ G. Nanni

Department of Surgery, Catholic University,

Rome, Italy
Keywords Bilio-pancreatic diversion $\cdot \mathrm{BMI}<35 \mathrm{~kg} / \mathrm{m}^{2}$. Hypocaloric diet · Insulin secretion · Insulin sensitivity . Type 2 diabetes
Abbreviations
BPD Bilio-pancreatic diversion
FFM Fat-free mass
ISR Insulin secretion rate

\section{Introduction}

Gastrointestinal surgery can induce long-term remission of type 2 diabetes in patients undergoing bariatric operations for morbid obesity [1]. Experiments in a non-obese type 2 diabetes rodent model demonstrated that surgical control of diabetes by gastrointestinal bypass is the direct effect of the anatomical rearrangement of the small bowel, independently of weight loss [2]. Surgical control of diabetes may thus be potentially obtained also in patients who do not meet current criteria for bariatric surgery (BMI $>40 \mathrm{~kg} / \mathrm{m}^{2}$ or BMI $>35 \mathrm{~kg} / \mathrm{m}^{2}$ with high-risk comorbid conditions). Recent reports corroborate this hypothesis showing that a variety of operations, including Roux-en-Y gastric bypass [3], duodenal-jejunal bypass [4] and gastric banding [5] can dramatically improve diabetes in patients with BMI $<35 \mathrm{~kg} / \mathrm{m}^{2}$. The physiological basis of the improvement in diabetes after surgery is still unclear; however, the dominant hypotheses involve changes in hormone signalling from the small bowel, which may influence insulin sensitivity, insulin secretion, or both.

In this pilot study, five type 2 diabetes patients (BMI 27$33 \mathrm{~kg} / \mathrm{m}^{2}$ ) underwent bilio-pancreatic diversion (BPD) in order to treat diabetes. The BPD group was compared with diabetes patients under an energy-restriction programme. 
The aims of the study were: (1) to evaluate the degree of glycaemic control and its durability in the short- to midterm; and (2) to determine insulin secretion and insulin sensitivity early after the operation, to investigate their role in the mechanisms involved in the rapid improvement of diabetes after gastrointestinal bypass surgery.

\section{Methods}

Ethics committee approval A group of five patients undergoing BPD was considered sufficient for the aims of this pilot study. Inclusion criteria were type 2 diabetes according to the American Diabetes Association criteria [6], $\mathrm{HbA}_{1 \mathrm{c}}$ $>7.5 \%$, BMI between 26 and $33 \mathrm{~kg} / \mathrm{m}^{2}$ and age between 30 and 60 years. Exclusion criteria were: type 1 diabetes, renal or hepatic failure, major psychological disorders, pregnancy and previous abdominal surgery. Neither gastric complications nor major side effects occurred following the surgical procedure. All patients received oral vitamin and iron supplementation and dietary suggestions. A matched group of type 2 diabetes patients (three women and four men) was selected from a large database including patients before and 1 month after a daily energy deficit of 2,090-4,180 kJ/day, calculated as resting energy expenditure $\times 1.4$ (measured by indirect calorimetry with a Deltatrac II Metabolic Monitor [Datex-Ohmeda Instrumentarium Corp., Helsinki, Finland]). Weight loss was $0.5-1.0 \mathrm{~kg} /$ week. The studies were approved by the Institutional Review Board and Ethics Committee of the Catholic University-Policlinico Gemelli (Rome, Italy). All patients gave written consent.

Surgical technique BPD was used since this is the standard of care for bariatric patients at our Institution. An open BPD was performed [7], although the majority of centres worldwide currently perform bariatric surgery using a laparoscopic approach to minimise risks. The procedure included a distal, horizontal gastrectomy which leaves behind a $300-400 \mathrm{~cm}^{3}$ sized upper stomach. This remnant stomach is anastomosed to the distal $250 \mathrm{~cm}$ of the small intestine (alimentary limb). The excluded small intestine (including the duodenum, jejunum and part of the ileum) carries the bile and pancreatic secretions (biliary limb) and is connected to the alimentary limb at $100 \mathrm{~cm}$ proximal to the ileocaecal valve to create the 'common limb', the only segment where bile and nutrients mix.

Outcome measures Body weight was measured to the nearest $0.1 \mathrm{~kg}$ by a beam scale, and height to the nearest $0.5 \mathrm{~cm}$ using a stadiometer (Holtain, Crymych, UK). Body composition was estimated by isotopic dilution [8]. $\mathrm{HbA}_{1 \mathrm{c}}$ levels were measured before and 1, 3, 6, 12 and 18 months after surgery and 1 month after the diet.
OGTT and chemical analyses A $75 \mathrm{~g}$ OGTT was performed in each patient at baseline and at 1 month after surgery or diet (blood sampling at 0, 30, 60, 90, 120 and $180 \mathrm{~min}$ ). Glycaemia was measured by the glucose oxidase method (Beckman, Fullerton, CA, USA). Insulinaemia was assayed by microparticle enzyme immunoassay (Abbott, Pasadena, CA, USA) with a sensitivity of $6 \mathrm{pmol} / \mathrm{l}$ and an intra-assay CV of $6.6 \%$. C-peptide was assayed by RIA (MYRIA; Technogenetics, Milan, Italy) with a minimal detectable concentration of $17 \mathrm{pmol} / 1$ and inter- and intra-assay CV values of $3.3-5.7 \%$ and $4.6-5.3 \%$, respectively. Fasting and total insulin secretion rate (ISR) after the OGTT were calculated by deconvolution of $\mathrm{C}$-peptide concentrations [9] and expressed in nmol $\mathrm{min}^{-1} \mathrm{~m}^{-2}$ body surface area. Total ISR was computed as the integral over the $3 \mathrm{~h}$ of the ISR after the OGTT. Insulin sensitivity was calculated from the OGTT by the oral glucose insulin sensitivity (OGIS), which provides an index that is analogous to the index of insulin sensitivity obtained from the glucose clamp [10].

Euglycaemic-hyperinsulinaemic clamp Peripheral insulin sensitivity was evaluated by a euglycaemic-hyperinsulinaemic clamp (EHC). Prior to the clamp, plasma glycaemia was maintained in a physiological range by an overnight insulin infusion. Whole-body glucose uptake was calculated with respect to fat-free mass (FFM) as the $M$ value ( $\mu \mathrm{mol} \mathrm{\textrm {kg } _ { \mathrm { FFM } }}{ }^{-1}$ $\min ^{-1}$ ) calculated during the last $40 \mathrm{~min}$ period of the steady-state insulin infusion.

Statistical analysis Data (means \pm SEM) were analysed by SPSS statistical software (version 13; SPSS, Chicago, IL, USA). The Wilcoxon signed-rank test was performed to compare data from the same patients before and after the interventions. ANOVA with repeated measures was used to detect glucose and insulin changes over time during the OGTT. Two-way ANOVA was performed to compare the BPD with the diet group. $p<0.05$ was set as significant.

\section{Results}

Between April 2006 and January 2007, five patients (two women and three men) underwent BPD. At the time of the first study, diabetes duration in both the BPD and diet groups ranged from 3 to 15 years and the patients were on either oral hypoglycaemic agents or insulin.

OGTT results at 1 month (after surgery and diet) One month after BPD, FFM, fat mass and $\mathrm{HbA}_{1 \mathrm{c}}$ were significantly reduced in both groups (Table 1). 
Table 1 Demographic and body composition data of the patients before and 1 month after BPD or diet, and 12 and 18 months after BPD only

\begin{tabular}{|c|c|c|c|c|c|c|}
\hline \multirow[t]{2}{*}{ Variable } & \multirow[t]{2}{*}{ Before BPD } & \multicolumn{3}{|l|}{ After BPD } & \multirow[t]{2}{*}{ Before diet } & \multirow{2}{*}{$\begin{array}{l}\text { After diet } \\
1 \text { month }\end{array}$} \\
\hline & & 1 month & 12 months & 18 months & & \\
\hline Age (years) & $48 \pm 3$ & & & & $51 \pm 3$ & \\
\hline Height (cm) & $175.20 \pm 4.49$ & & & & $169.28 \pm 1.21$ & \\
\hline BMI $\left(\mathrm{kg} / \mathrm{m}^{2}\right)$ & $30.94 \pm 1.05$ & $30.00 \pm 0.80$ & $25.37 \pm 0.01$ & $25.07 \pm 0.01$ & $29.98 \pm 1.70$ & $29.18 \pm 1.78$ \\
\hline$p$ value & & 0.048 & 0.043 & 0.043 & & 0.018 \\
\hline Weight (kg) & $95.60 \pm 7.24$ & $92.60 \pm 6.40$ & $77.80 \pm 3.54$ & $76.80 \pm 2.96$ & $86.00 \pm 5.20$ & $83.71 \pm 5.46$ \\
\hline$p$ value & & 0.046 & 0.042 & 0.040 & & 0.017 \\
\hline Fat mass $(\mathrm{kg})$ & $35.00 \pm 3.40$ & $33.52 \pm 3.14$ & $25.58 \pm 1.16$ & $24.67 \pm 1.77$ & $29.24 \pm 3.10$ & $28.73 \pm 3.12$ \\
\hline$p$ value & & 0.043 & 0.043 & 0.043 & & 0.018 \\
\hline FFM (kg) & $60.60 \pm 4.60$ & $59.08 \pm 4.26$ & $52.22 \pm 2.38$ & $52.13 \pm 2.71$ & $55.76 \pm 2.97$ & $54.98 \pm 3.22$ \\
\hline$p$ value & & 0.039 & 0.049 & 0.049 & & 0.018 \\
\hline $\mathrm{HbA}_{1 \mathrm{c}}(\%)$ & $8.48 \pm 0.24$ & $7.18 \pm 0.30$ & $5.62 \pm 0.24$ & $5.7 \pm 0.23$ & $8.78 \pm 0.40$ & $8.6 \pm 0.31$ \\
\hline$p$ value & & 0.039 & 0.043 & 0.042 & & 0.042 \\
\hline
\end{tabular}

Data are means \pm SEM

$p$ values were determined by Wilcoxon signed-rank test before vs after BPD or diet

Although both interventions allowed a reduction of plasma glucose levels over time, glycaemia after OGTT was significantly (as asterisked in Fig. 1a) lower after BPD than after diet ( $2 \mathrm{~h}$ plasma glucose: $15.22 \pm 3.22$ and $6.22 \pm$ $0.51 \mathrm{mmol} / \mathrm{l}$, before and after BPD, respectively, $p=0.043$ ). In contrast, with the exception of fasting insulin, insulin levels did not differ significantly between diet and BPD groups, probably as a consequence of quite a large interindividual variability (Fig. 1b). After BPD, plasma insulin concentration decreased from $94.80 \pm 14.00$ to $37.80 \pm$ $3.23 \mathrm{pmol} / \mathrm{l}(p=0.004)$ at fast and from $359.88 \pm 115.82$ to $121.65 \pm 35.67 \mathrm{pmol} / \mathrm{l} 2 \mathrm{~h}$ after the glucose load $(p=\mathrm{NS})$.

ISR did not differ significantly between groups. Fasting ISR was $0.90 \pm 0.22$ before and $0.99 \pm 0.96 \mathrm{nmol} \mathrm{min}{ }^{-1} \mathrm{~m}^{-2}$ after BPD ( $p=\mathrm{NS})$ and $1.08 \pm 0.17$ before and $0.95 \pm$ $0.12 \mathrm{nmol} \mathrm{min}{ }^{-1} \mathrm{~m}^{-2}$ after diet ( $p=\mathrm{NS}$ ). Despite not being statistically significant, total ISR showed a decreasing trend from $17.63 \pm 8.07$ to $9.06 \pm 3.91 \mathrm{nmol} \mathrm{min}{ }^{-1} \mathrm{~m}^{-2}$ after BPD. In contrast, total ISR remained practically unchanged after diet (from $17.04 \pm 6.89$ to $14.43 \pm 4.16 \mathrm{nmol} \mathrm{min}{ }^{-1} \mathrm{~m}^{-2}$ ). Interestingly, insulin sensitivity was higher after BPD than after diet $(p=0.013)$, as assessed by the OGIS index ( $330 \pm$ 19.78 before and $425 \pm 15.27 \mathrm{ml} \mathrm{min}^{-1} \mathrm{~m}^{-2}$ after BPD, $p=$ 0.043 and $360 \pm 19.70$ before and $392 \pm 14.43 \mathrm{ml} \mathrm{min}^{-1} \mathrm{~m}^{-2}$ after diet, $p=0.398$ ).

Before BPD, total ISR logarithmically decreased with the increase of diabetes duration $\left(y=-25.569 \log _{e}(x)+\right.$ 65.118; $R^{2}=0.86$ ). An unexpected result was that in a single patient, whose ISR before surgery was almost undetectable and diabetes onset was 15 years before BPD, the ISR both at fast and after OGTT had a relevant rise
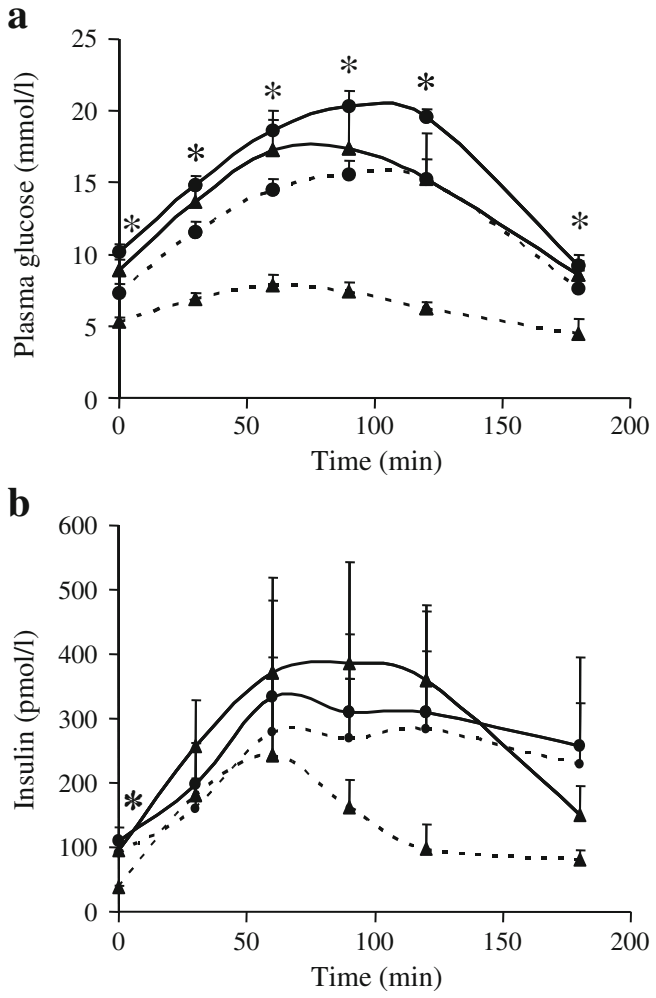

Fig. 1 Glucose (a) and insulin (b) levels during the $3 \mathrm{~h}$ OGTT in patients before (continuous lines) and after (dashed lines) diet (circles) or BPD (triangles). Data are means \pm SEM. ${ }^{*} p<0.05$ between groups after BPD or diet 


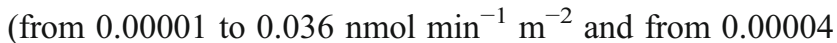

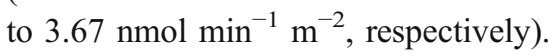

Clamp results at 1 month after surgery One month after BPD, insulin-mediated whole-body glucose uptake significantly $(p=0.043)$ increased from $16.64 \pm 0.56$ to $30.80 \pm$ $0.86 \mu \mathrm{mol} \mathrm{\textrm {kg } _ { \mathrm { FFM } }}{ }^{-1} \mathrm{~min}^{-1}$. Average insulin levels at the EHC steady state significantly $(p=0.043)$ decreased from $104.80 \pm 6.80$ to $85.20 \pm 3.90 \mathrm{pmol} / \mathrm{l}$, suggesting an increase in hepatic insulin clearance. A significant $(p=0.032)$ correlation between $M$ value and total insulin secretion was observed $\left(y=1 \times 10^{7} \times \mathrm{e}^{-0.2052 x} ; R^{2}=0.83\right)$.

Changes in body composition and diabetes compensation up to 18 months after surgery BMI decreased from 30.94t 1.05 to $25.36 \pm 0.93 \mathrm{~kg} / \mathrm{m}^{2}(p=0.043) 12$ months after BPD and remained constant at $25.07 \pm 0.88 \mathrm{~kg} / \mathrm{m}^{2} \quad(p=0.043)$ after 18 months. $\mathrm{HbA}_{1 \mathrm{c}}$ levels were significantly reduced at 3 and 6 months $(6.28 \pm 0.33 \%, p=0.042$, and $5.88 \pm 0.29 \%$, $p=0.042$, respectively) and fully normalised after 12 and 18 months (Table 1 ).

\section{Discussion}

Gastrointestinal surgery as a treatment for type 2 diabetes in mildly obese or non-obese patients has recently become a matter of intense debate. Only a few studies have reported on the efficacy of gastrointestinal surgery in non-obese diabetes patients using standard Roux-en-Y gastric bypass [3], gastric banding [4] or novel procedures such as duodenal-jejunal bypass [5].

This is the first prospective case series study showing that BPD can achieve rapid, complete and stable remission of type 2 diabetes in patients with BMIs between 27 and $33 \mathrm{~kg} / \mathrm{m}^{2}$. Compared with the energy-restricted group, BPD produced a larger decrease in glycaemia, both at fast and during a $3 \mathrm{~h}$ OGTT, a reduced fasting insulinaemia and a net improvement of insulin sensitivity at 1 month.

Further studies and long-term data are needed to evaluate the effect of BPD on insulin secretion and sensitivity in type 2 diabetes patients with $\mathrm{BMI}<35 \mathrm{~kg} / \mathrm{m}^{2}$, as well as its effects on incretins, appetite-regulating hormones and adipokines.

Our preliminary study, at 1 month, indicates the efficacy of BPD in the treatment of type 2 diabetes in patients with BMI $<35 \mathrm{~kg} / \mathrm{m}^{2}$ as compared with diet. Larger clinical studies are needed to identify new variables for patients' selection irrespectively of BMI levels.

Acknowledgement We thank A. Caprodossi for her expert technical assistance.

Duality of interest The authors declare that there is no duality of interest associated with this manuscript.

\section{References}

1. Buchwald H, Avidor Y, Braunwald E et al (2004) Bariatric surgery: a systematic review and meta-analysis. JAMA 292:17241737

2. Rubino F, Forgione A, Cummings D et al (2006) The mechanism of diabetes control after gastrointestinal bypass surgery reveals a role of the proximal small intestine in the pathophysiology of type 2 diabetes. Ann Surg 244:741-749

3. Lee WJ, Wang W, Lee YC, Huang MT, Ser KH, Chen JC (2008) Effect of laparoscopic mini-gastric bypass for type 2 diabetes mellitus: comparison of BMI $>35$ and $<35 \mathrm{~kg} / \mathrm{m}^{2}$. J Gastrointest Surg 12:945-952

4. Cohen RV, Schiavon CA, Pinheiro JS, Correa JL, Rubino F (2007) Duodenal-jejunal bypass for the treatment of type 2 diabetes in patients with body mass index of $22-34 \mathrm{~kg} / \mathrm{m}^{2}$ : a report of 2 cases. Surg Obes Relat Dis 3:195-197

5. Dixon JB, O'Brien PE, Playfair J et al (2008) Adjustable gastric banding and conventional therapy for type 2 diabetes: a randomized controlled trial. JAMA 299:316-323

6. Genuth S, Alberti KG, Bennett P et al (2003) Follow-up report on the diagnosis of diabetes mellitus. Diabetes Care 26:3160-3167

7. Scopinaro N, Gianetta E, Civalleri D, Bonalumi U, Bachi V (1979) Bilio-pancreatic bypass for obesity: II. Initial experience in man. Br J Surg 66:618-620

8. Guidone C, Manco M, Valera-Mora E et al (2006) Mechanisms of recovery from type 2 diabetes after malabsorptive bariatric surgery. Diabetes 55:2025-2031

9. van Cauter E, Mestrez F, Sturis J, Polonsky KS (1992) Estimation of insulin secretion rates from C-peptide levels: comparison of individual and standard kinetic parameters for C-peptide clearance. Diabetes 41:368-377

10. Mari A, Pacini G, Murphy E, Ludvik B, Nolan JJ (2001) A model-based method for assessing insulin sensitivity from the oral glucose tolerance test. Diabetes Care 24:539-548 